University for Business and Technology in Kosovo

UBT Knowledge Center

UBT International Conference

2017 UBT International Conference

Oct 28th, 4:00 PM - 5:50 PM

\title{
Seismic actions induced by cladding panels on precast concrete frame structures
}

Bruno Del Lago

Politecnico di Milano

Francesco Foti

Politecnico di Milano

Luca Martinelli

Politecnico di Milano

Follow this and additional works at: https://knowledgecenter.ubt-uni.net/conference

Part of the Civil Engineering Commons

\section{Recommended Citation}

Del Lago, Bruno; Foti, Francesco; and Martinelli, Luca, "Seismic actions induced by cladding panels on precast concrete frame structures" (2017). UBT International Conference. 38.

https://knowledgecenter.ubt-uni.net/conference/2017/all-events/38

This Event is brought to you for free and open access by the Publication and Journals at UBT Knowledge Center. It has been accepted for inclusion in UBT International Conference by an authorized administrator of UBT Knowledge Center. For more information, please contact knowledge.center@ubt-uni.net. 


\title{
Seismic actions induced by cladding panels on precast concrete frame structures
}

\author{
Bruno Dal Lago ${ }^{1}$, Francesco Foti ${ }^{1}$, LucaMartinelli ${ }^{1}$ \\ ${ }^{1}$ Department of Civil and Environmental Engineering, Politecnico di Milano, \\ Piazza Leonardo da Vinci 32, 20133 Milano \\ bruno.dallago@polimi.it
}

\begin{abstract}
The strong earthquakes occurred in Southern Europe in the last decade pointed out a poor seismic performance of the connection system of the cladding of precast industrial structures. The cladding of these buildings usually consists of sandwich concrete panels of remarkable mass, connected to the frame structure with mechanical devices. The estimation of the out-of-plane seismic action on these connections is a key step for their correct proportioning. However, the formulation currently provided in the Eurocode 8 for the estimation of the seismic action on non-structural elements was calibrated with different objectives. Furthermore, given there is no in-plane structure-panel interaction, a quote of the panel mass is lumped in correspondence of their connection for a correct proportioning of the frame structure. The designers need to make assumptions on both aspects that often bring to remarkably different solutions. The paper presents a rigorous dynamic formulation of the problem of the vibration of rigid bodies connected with cantilever columns. The solution brings to analytical expressions to evaluate the exact out-of-plane action on the connections and the correct amount of panel mass to be lumped.
\end{abstract}

Keywords: Precast structures, Cladding panels, Seismic actions, Mechanical connections.

\section{Introduction}

Recently in Europe three violent earthquakes occurred in highly industrialised areas; they represented a severe check for precast structures as for any other type of structures. Mainly industrial one-storey buildings were involved. The experience of these earthquakes, further to confirm the validity of the code provisions for the design of the main precast structure, showed that there is still a pending problem for the good behaviour of the overall building. This problem refers to the correct design of the connections of the wall panels to the structural frame. The possible collapse of these panels, with weights up to 12 tons, represents a mortal danger for human lives and a heavy direct and indirect economic loss for the community. Fig. 1 shows an emblematic picture of an industrial building just after L'Aquila (Italy) earthquake of 2009: the main structure made of columns, beams and roof elements is practically undamaged; an entire façade of wall panels collapsed down. A general description of the effects of that earthquake on precast structures can be found in [01]. Also Lorca (Spain) and Van (Turkey) earthquake of 2011 led to a relevant number of these situations (see Fig. 2). In Emilia (Italy) on 2012, where at the construction time the seismic design code was not in force, also when the main structure did not collapse many falls of panels occurred (see Fig. 3). General descriptions of the effects of the latter earthquake on precast structures can be found in [02-05].

As a consequence of these events, the scientific community gained growing awareness about the problem of the seismic interaction of the cladding system with the structure. In particular, 
the current design methodology of the mechanical cladding connections concerns the evaluation of a seismic action out of the plane of the panel only, which is calculated according to the EuroCode 8 [06] formulation for non-structural components and with reference to the mass of the single panel. However, the cladding panels are in practice typically connected with strap connections [07] which are not conceived to allow for relative in-plane displacements. This makes the stiff panels participate to the lateral load resisting systems, causing strong actions in the plane of the panel to rise and adding an important and unpredicted component to the seismic action on the single connections. A recently ended 3-year European research project named Safecladding (FP7-SME-2012, GA 314122/2012) provided a systematic framing of the problem of the seismic design of precast frame structures with cladding panels [08]. Within this project, a wide set of fastening devices and structural arrangements has been submitted to a campaign of experimental checks by means of a large number of tests performed at different levels, from local to global scale $[09,10]$ (Fig. 4).

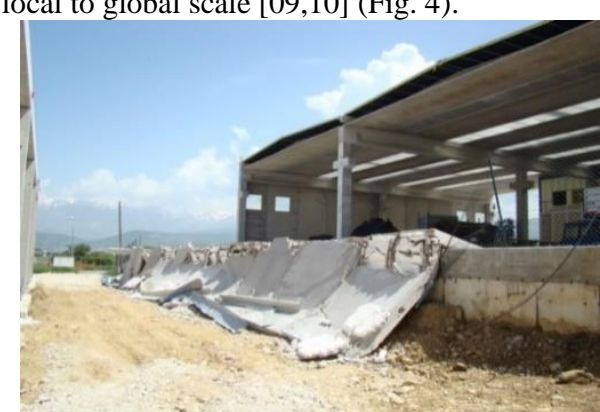

Fig. 1.L'Aquila 2009: struct OK, panelsKO.

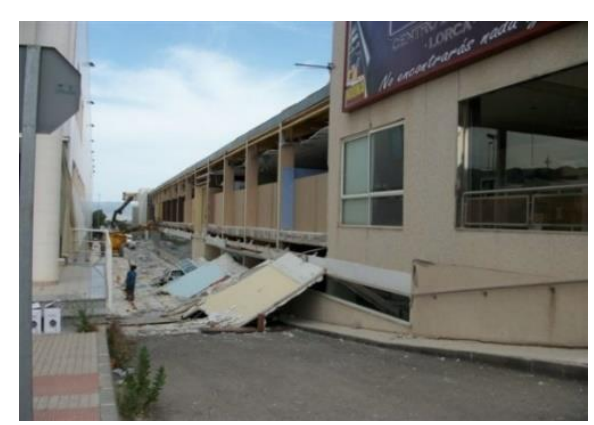

Fig. 2.Lorca 2011: structure OK, panels KO.

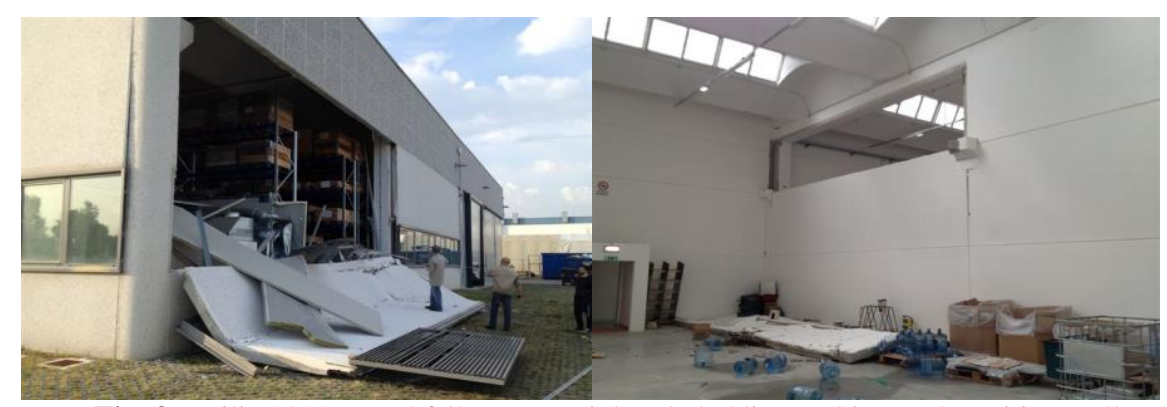

Fig. 3.Emilia 2012: panel failures - peripheral cladding and internal partition walls.

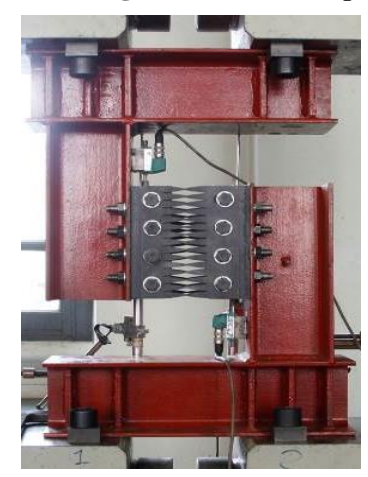

(a)

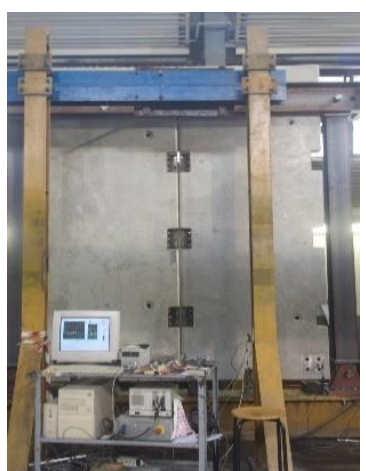

(b)

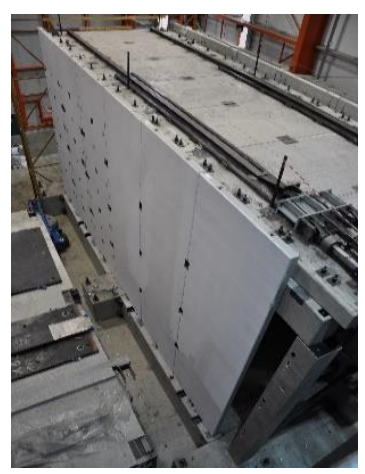

(c) 
Fig. 4. Safecladding project: (a) local tests on devices at POLIMI, (b) panel sub-assembly test at POLIMI, (c) full-scale prototype tests of precast structure at ELSA.

While the proposed design framework allowed to choose the proper static schemes and technological solutions to link the cladding panels to the structure, including isostatic solutions that allow for an in-plane decoupling of the cladding panels, the affordability of the application of the EC8 formula to evaluate the out-of-plane loads on the connections has not been rigorously verified. Recently, Belleri et al. [11] carried out a numerical investigation on this issue with reference to horizontal panels, showing that this formulation is often not on the safe side. Furthermore, the designers properly include a ratio of the mass of the cladding panels lumped at the roof level. However, they are not provided with a rule to properly define this ratio, and usually they make assumptions that may be very different.

The present paper aims at providing a rigorous dynamic formulation of the problem of the seismic vibration of a precast one-storey frame structure with vertical cladding panels.

\section{Formulation of the Problem}

A simple structural scheme (Fig. 5) is considered in this work to investigate the dynamic response of an archetypal one-storey precast concrete structure subjected to seismic loads. A rigid cladding panel with total mass $m_{p}$ is hinged at the base (point $A$ in Fig. 5a) and connected to a flexible cantilever by means of a rigid truss element. The mass $m_{t o p}$ is lumped at the top of the cantilever (point $C$ in Fig. 5a), to model the effect of the translational inertia forces due to the mass of the roof. Given the roof diaphragm is rigid, the cantilever can model the whole lateral load resisting system, and the rigid element can model all panels in the orthogonal direction with respect to the input seismic action. The influence of the panels lying in the direction parallel to the input seismic action depend on their connection system. For instance, if they are connected with a cantilever arrangement (sliding connection at the top), their mass can be neglected [9]. Conversely, if they are connected with a pendulum arrangement (hinged at top and bottom), their mass shall be added to that of the panels in the orthogonal direction [9]. In the case of a disarticulated diaphragm, the present procedure is valid for single frames.

By neglecting the axial deformability of the flexible cantilever, the kinematics of the structure can be completely described by means of a single Lagrangian coordinate, such as the horizontal displacement $q(t)$ (the symbol $t$ denotes the time) of the top of the cantilever with respect to its base. Fig. $5 \mathrm{~b}$ shows the deformed shape of the structure subjected to the ground motion $u(t)$.

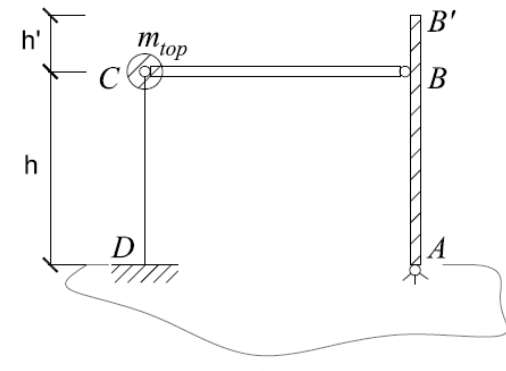

(a)

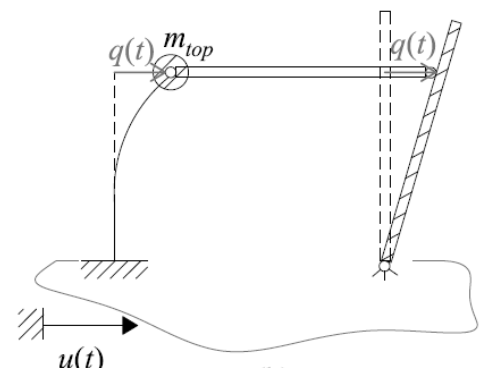

(b)

Fig. 5. Structure at study: (a) Reference configuration, (b) Deformed configuration under the effect of the ground motion $u(t)$. 
The kinetic energy, $\mathrm{K}(\mathrm{t})$, and the elastic strain energy, $\mathrm{E}(\mathrm{t})$, of the system can be expressed, respectively, as:

$$
\begin{aligned}
& K(t)=\frac{1}{2} m_{t o p}(\dot{u}(t)+\dot{q}(t))^{2}+\frac{1}{2} m_{p}\left(\dot{u}(t)+\frac{1}{2}(1+\eta) \dot{q}(t)\right)^{2}+\frac{1}{2} \frac{m_{p}}{12}(1+\eta)^{2} \dot{q}^{2}(t) \\
& E(t)=\frac{1}{2} k_{c o l} q^{2}(t) .
\end{aligned}
$$

where: a dot is adopted to denote derivatives with respect to the time; kcol is the generalized stiffness of the flexible cantilever; and $\square$ is the non-dimensional ratio: $\square \square=h^{\prime} / \mathrm{h}$. The values of the geometric parameter $\square$ may be assumed in the range: $0 \leq \square \square \square \leq 1 / 3$, to cover the vast majority of the cases of practical interest.

It's worth noting that the third term on the right-hand side of Eq. (1), which represents the effect of the rotational kinetic energy of the cladding panel with respect to its centroid, has been evaluated under the assumption, commonly verified in practice, of uniform mass distribution along the height of the panel.

By defining the Lagrangian function: $\mathrm{L}=\mathrm{K}-\mathrm{E}$, the equation of motion of the system can be derived, through a classic variational approach [12], as:

$\frac{d}{d t}\left(\frac{\partial L}{\partial \dot{q}}\right)-\frac{\partial L}{\partial q}=0$.

By substituting Eqs. (1) and (2) in (3), the following equation can be obtained:

$\ddot{q}(t)+\omega_{1}^{2} q(t)=-r \ddot{u}(t)$

The term $\omega_{1}$ is the natural circular frequency of the structure, which is related to its period, $T_{1}$, through the well-known relation: $\omega_{1}=2 \pi / T_{1}$. The term $r$ is the mass participation factor for the considered seismic excitation. The expressions for the natural period $T_{1}$ and for the mass participation $r$ are fully detailed in the following.

By denoting as $T_{0}$ the natural period of the structure calculated by neglecting the effect of the mass of the panel (i.e. $\left.T_{0}=2 \pi\left(m_{t o p} / k_{c o l}\right)^{1 / 2}\right)$, and by defining the non-dimensional parameter $\mu$ as the ratio between the mass of the panel and the lumped mass $m_{t o p}$, i.e.: $\mu=m_{p} / m_{t o p}$, the period $T_{1}$ of the structure can be expressed as:

$T_{1}=T_{0} \cdot \chi_{T}(\mu, \eta)$.

where $\chi_{T}$ is a non-dimensional correction factor accounting for the effects of the cladding panel mass on the natural period of the structure and can be calculated as:

$\chi_{T}(\mu, \eta)=\sqrt{1+\mu(1+\eta)^{2} / 3}$.

The mass participation factor $r$, which fully accounts for both the translational and rotational inertia of the cladding panel, can be expressed as:

$r=\left(1+\mu(1+\eta)^{2} / 3\right) /(1+\mu(1+\eta) / 2)$.

Figs. $6 \mathrm{a}$ and $6 \mathrm{~b}$ depict, respectively, the correction coefficient $\chi_{T}$ and the participation factor $r$ as a function of the mass ratio $\mu$. The mass ratio is assumed to be variable in the range: $0.5 \leq \mu \leq 2.5$, which covers most cases of practical interest. The results are shown for $\eta=0$ and $\eta=1 / 3$.

The correction factor $\chi_{T}$ remarkably increases almost linearly with both $\mu$ and $\eta$. The higher $\mu$, the higher the global vibrating mass of the system; the higher $\eta$, the higher the inertial effects associated to the panel rotation. The mass participation factor $r$ is closer to the unity for increasing values of $\eta$. This is expectable, since the position of the application point of the resultant of the panel inertia forces moves closer to the height of point $B$. 
The linear Eq. of motion (4) can be easily extended in order to include a linear viscous damping term to account for the structural dissipation. Standard solution techniques, then, can be applied to obtain the relative displacement time history, $q(t)$, for an assigned seismic input [13].

Once $q(t)$ is known, the horizontal forces acting on $A$ and $B$, denoted as $F_{A}$ and $F_{B}$, respectively, can be obtained by imposing the dynamic equilibrium of the panel:

$$
\begin{aligned}
& F_{A}(t)=\frac{1}{2} \eta\left(1-\frac{2}{3} \eta^{2}\right) m_{p} \ddot{q}(t)+\left(1-\frac{\eta}{2}\right) m_{p} \ddot{u}(t) . \\
& F_{B}(t)=\frac{1}{3} \eta^{2} m_{p} \ddot{q}(t)+\frac{\eta}{2} m_{p} \ddot{u}(t) .
\end{aligned}
$$

The Eqs. (8) and (9) can be assumed as a basis for a consistent estimation of the out-of-plane seismic action acting on the connections $A$ and $B$.
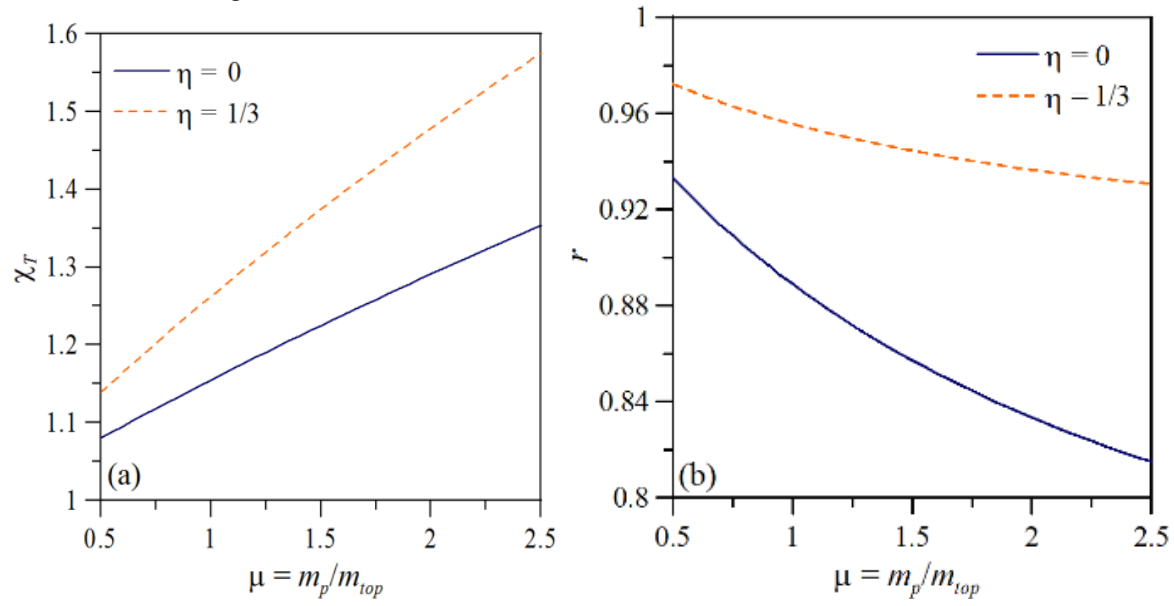

Fig. 6.Parametric analysis: (a) Natural period correction factor $\square$ T, (b) Participation factor $r$.

\section{Conclusion}

The problem of the proper evaluation of the effects of the coupled vibration of precast frame structures and their cladding panels under seismic action has been set within a rigorous dynamic framework. This allowed to obtain closed-form equations for the correction factor of the natural vibration period of the structure and the mass participation factor. Analytical expressions of the seismic actions on the panel connections have also been obtained, as a function of both the relative acceleration of the roof and of the absolute acceleration of the ground. This makes the usual response spectrum approach not straightforwardly applicable. Further efforts will be devoted to developing a more design-oriented procedure. Furthermore, the present methodology will be applied also to the case of horizontal cladding panels.

Acknowledgments. The work of the second and third authors has been partially supported by MIUR (Italian Ministry of Education, University and Research) under the project "PRIN 20152018 - Identification and monitoring of complex structural systems". 


\section{References}

1. Toniolo, G., Colombo, A.: Precast concrete structures: the lesson learnt from L'Aquila earthquake. Struct. Conc. 13(2) (2012) 73-83

2. Ozden, S., Akpinar, E., Erdogan, H., Atalay, H.: Performance of precast concrete structures in October 2011 Van earthquake, Turkey. Mag. Concr. Res. 66(11) (2014) 543-552

3. Bournas, D., Negro, P., Taucer F.: Performance of industrial buildings during the Emilia earthquakes in Northern Italy and recommendations for their strengthening. Bull. Earthq. Eng. 12(5) (2013) 2383-2404

4. Magliulo, G., Ercolino, M., Petrone, C., Coppola, O., Manfredi, G.: Emilia earthquake: the seismic performance of precast RC buildings. Earthq. Spectra 30(2) (2014) 891-912

5. Belleri, A., Brunesi, E., Nascimbene, R., Pagani, M., Riva, P.: Seismic performance of precast industrial facilities following major earthquakes in the italian territory. J. Perf. Constr. Fac., ASCE, 29(5) (2015) 04014135

6. EN 1998-1:2004. Eurocode 8: Design of structures for earthquake resistance. Part 1: General rules, seismic actions and rules for buildings. CEN, Brussels, Belgium

7. Zoubek, B., Fischinger, M., Isaković, T.: Cyclic response of hammer-head strap claddingto-structure connections used in RC precast buildings. Eng. Struct. 119 (2016) 135-148

8. Biondini, F., Dal Lago, B., Toniolo, G.: Role of wall panel connections on the seismic performance of precast structures. Bull. Earthq. Eng. 11(4) (2013) 1061-1081

9. Toniolo, G., Dal Lago, B.: Conceptual design and experimentation on wall panel connection systems of precast buildings. Earthq. Eng. Struct. Dyn. (2017). doi:10.1002/eqe.2918

10. Negro, P., Lamperti, M.: Seismic response of precast structures with vertical cladding panels: The SAFECLADDING experimental campaign. Eng. Struct. 132 (2017) 205-228

11. Belleri, A., Cornali, F., Passoni, C., Marini, A., Riva, P.: Evaluation of out-of-plane seismic performance of column-to-column precast concrete cladding panels in one-storey industrial buildings. Earthq. Eng. Struct. Dyn. (2017) doi: 10.1002/eqe.2956

12. Géradin, M., Rixen, D.: Mechanical Vibrations, Wiley \& Sons, Chichester (England), 1997

13. Clough, R.W., Penzien, J.: Dynamics of structures, McGraw-Hill, New York (USA), 1975 